\section{Job strain, health behaviours and heart disease}

We read with interest the study by Kivimaki and colleagues, ${ }^{1}$ which examines the longitudinal relationship between job strain and health behaviours on coronary heart disease. Their findings support previous Canadian research ${ }^{2}$ that suggests psychosocial working conditions play an important role in the etiology of chronic health conditions. We were, however, surprised by the authors' conclusion that suggests that when a patient's job strain and lifestyle factors contribute to heart disease, clinicians should tell those patients to simply adopt a healthier lifestyle. ${ }^{1}$

That low socioeconomic position is associated with both lower job control and poorer health behaviours is well established. ${ }^{3}$ That individualistic approaches to improving health behaviours do not improve - and can exacerbate - social inequalities in health is also well established. ${ }^{4}$ Although we agree with Kivimaki and colleagues ${ }^{1}$ that changing the psychosocial work environment is challenging, it is possible with concerted efforts from management and employees. ${ }^{5}$ In addition, although primary prevention programs, such as physical activity, continue to have limited success at the population level, these programs still seem to be at the forefront of many approaches to improve the health of the population. Telling a patient who experiences a high level of job strain to lose weight is likely as effective as telling a patient who is overweight to find a better job, which based on this study, would confer some decreased risk.

We also question using obesity as a lifestyle factor. People don't start or stop being obese like they start smoking, drinking or being inactive. Obesity would be better conceptualized as a mediating factor between both health behaviours and job strain, and cardiovascular disease. This grouping would allow a more realistic estimate of the risks associated with lifestyle factors, noting that apart from smoking, the hazard ratios associated with job strain were similar to those of alcohol and physical inactivity.

Work is an increasingly important part of the lives of many Canadians. Real progress on reducing the incidence of chronic diseases such cardiovascular disease and obesity are likely to be made by better understanding the relationships between health behaviours and working conditions (including job strain) rather than treating them as separate approaches to primary prevention.

\section{Peter M. Smith PhD MPH, Cameron A.} Mustard ScD

School of Public Health and Preventive Medicine (Smith), Monash University, Melbourne, Australia; Institute for Work \& Health, Toronto, Ont., Dalla Lana School of Public Health, University of Toronto, Toronto, Ont. (Smith, Mustard)

\section{References}

1. Kivimäki M, Nyberg ST, Fransson EI, et al. Associations of job strain and lifestyle risk factors with risk of coronary artery disease: a meta-analysis of individual participant data. CMAJ 2013;185:763-9.

2. Smith PM, Glazier RH, Lu H, et al. The psychosocial work environment and incident diabetes in Ontario, Canada. Occup Med (Lond) 2012;62:413-9.

3. Mustard CA, Vermeulen M, Lavis JN. Is position in the occupational hierarchy a determinant of decline in perceived health status? Soc Sci Med 2003;57: 2291-303.

4. Frohlich KL, Potvin L. The inequality paradox: the population approach and vulnerable populations. Am J Public Health 2008;98:216-21.

5. Bourbonnais R, Brisson C, Vinet A, et al. Effectiveness of a participative intervention on psychosocial work factors to prevent mental health problems in a hospital setting. Occup Environ Med 2006;63:335-42.

CMAJ 2013. DOI:10.1503/cmaj.113-2135

\section{Generic controlled-release oxycodone}

We wish to respond to Miller's article in CMAJ. ${ }^{1}$ The US Food and Drug Administration (FDA) approved abuse-deterrent labelling for reformulated OxyContin in the United States. The new labelling indicates that the product has physical and chemical properties that are expected to make abuse via injection difficult and to reduce abuse via the intranasal route (snorting). In addition, the FDA determined that the original OxyContin was withdrawn from sale for reasons of safety or effectiveness and, accordingly, the agency will not accept or approve any abbreviated new drug applications (generics) that rely upon the approval of the original OxyContin. ${ }^{2}$

All available postmarketing assessments of the impact of reformulated OxyContin (OxyNEO in Canada) on abuse, as well as the FDA's draft Guidance for Industry: Abuse-Deterrent Opioids - Evaluation and Labeling, ${ }^{3}$ were available to former federal health minister Leona Aglukkaq.

We are not in the market for a revival of the "cross-border controlledrelease oxycodone shopping" that was observed near the Detroit-Windsor Tunnel between August 2010 and October 2011, at a time when the original OxyContin remained available in Canada and the reformulated OxyContin had been introduced in the US. ${ }^{4}$

The FDA has now provided the evidence-based guidance former minister Aglukkaq alluded to in her March 2013 letter to the Commissioner of the FDA. The health minister now needs to protect the health and safety of all our communities and take concrete action to reduce risk by removing generic controlled-release oxycodone from the Canadian market.

Philip A. Baer MDCM, Joel Bordman MD, Erica L. Weinberg MD

Chair, Section on Rheumatology, Ontario

Medical Association, Toronto, Ont., and Member of Executive, Ontario Rheumatology Association, and Editor-in-Chief, Journal of the Canadian Rheumatology Association (Baer), Newmarket, Ont.; Medical Director, Complex Pain Program, First Steps Clinics, Toronto, Ont. (Bordman); and physician (Weinberg), Toronto, Ont.

Competing interests: Erica Weinberg: Janssen, Lilly, Medical Futures Inc., Purdue Pharma, Valeant; Philip Baer: Janssen, Purdue Pharma; Joel Bordman: Janssen, Purdue Pharma, Pfizer, Nycomed, Paladin Labs, King Pharma Lilly, Bayer, Schering-Plough, Valeant, Boehringer Ingelheim

\section{References}

1. Miller A. Aglukkaq asks for US help to control oxycodone CMAJ 2013;185:E317-8.

2. FDA approves abuse-deterrent labeling for reformulated OxyContin [media release]. Silver Spring (MD): US Food and Drug Administration; 2013. Available: www.fda.gov/NewsEvents/Newsroom /PressAnnouncements/ucm 348252.htm (accessed 2013 May 10). 